\title{
Risk factors for hyperactive delirium among ICU adult patients in southern Brazil: a prospective cohort study
}

\author{
RPd Oliveira*, R Rosa, A Ascoli, W Rutzen, L Madeira, P Balzano, P Morandi, V Souto, F Vargas, L Lago, C Dietrich, \\ J Rezende, F Ghizzoni, MC Souza, C Guterres, M Falavigna, K Lima, C Robinson, R Ribeiro, J Maccari, C Teixeira
}

From ESICM LIVES 2015

Berlin, Germany. 3-7 October 2015

\section{Introduction}

Delirium is associated with worse outcomes among intensive care unit (ICU) patients. Data about risk factors for delirium in Latin American ICUs are scarce.

\section{Objectives}

To determine risk factors associated with hyperactive delirium among ICU adult patients in Southern Brazil.

\section{Methods}

A multicenter prospective cohort study was performed with all consecutive adult patients admitted to mixed medical-surgical ICUs in Southern Brazil between May 2014 and December 2014. The present study is part of BaSICS (Brazilian Study of Post Intensive Care Syndrome). Hyperactive delirium was diagnosed by the confusion assessment method for the intensive care unit (CAM-ICU). A stepwise logistic regression was conducted to determine factors associated with incidence of hyperactive delirium during ICU stay.

\section{Results}

During the study period 124 patients were evaluated. The mean age and APACHE-II score were 64.5 years (SD 16.5) and 14.1 points (SD 5.3), respectively. The mean ICU length of stay was 8.8 days (SD 9.5). The overall incidence of hyperactive delirium was $25.8 \%$ (32 patients). Upon multivariate logistic regression analysis, parenteral sedation need during ICU stay (OR, 9.59; 95\%CI, 3.42-26.9) and Charlson comorbidity index (OR, 1.33; $95 \% \mathrm{CI}, 1.08-1.63$ ) were risk factors for hyperactive delirium. On the other hand, admission in a single-bed
ICU room (OR, 0.15; 95\%CI, 0.04-0.50) was a protective factor against hyperactive delirium during ICU stay.

\section{Conclusions}

Delirium in the intensive care unit (ICU) is exceedingly common, and risk factors for delirium among the critically ill are nearly ubiquitous. Nevertheless, maybe the action on the modifiable risk factors (eg, sedation management), and changes in architecture of the ICU could help to prevent the appearance of this syndrome.

Published: 1 October 2015

\section{References}

1. Caruso P, Guardian L, Tiengo T, Dos Santos LS, Junior PM: ICU architectural design affects the delirium prevalence: a comparison between singlebed and multibed rooms. Crit Care Med 2014, 42(10):2204-10.

2. Burry L, Rose L, McCullagh IJ, Fergusson DA, Ferguson ND, Mehta S: Daily sedation interruption versus no daily sedation interruption for critically ill adult patients requiring invasive mechanical ventilation. Cochrane Database Syst Rev 2014, 7:CD009176, Jul 9.

doi:10.1186/2197-425X-3-S1-A331

Cite this article as: Oliveira et al:: Risk factors for hyperactive delirium among ICU adult patients in southern Brazil: a prospective cohort study. Intensive Care Medicine Experimental 2015 3(Suppl 1):A331. 